\title{
Recommendations pertaining to the use of viral vaccines: Influenza 2010
}

\section{Background}

During 2009 South Africa experienced two epidemics of influenza - the first, from May to late June, due predominantly to seasonal influenza A (H3N2), and the second due to pandemic influenza A (H1N1). Both of these subtypes could be anticipated to cause significant illness burden during 2010: (i) the H3N2 virus has drifted significantly and may well be responsible for a major outbreak in 2010, affecting especially the elderly; and (ii) the pandemic influenza A (H1N1) (swine flu) will in all probability reappear as a dominant influenza strain during 2010. The impact of this is unpredictable, but it will in all likelihood affect younger individuals as occurred during 2009.

\section{Vaccine formulation for 2010}

The following strains have been recommended by the World Health Organization (WHO) for the 2010 Southern Hemisphere vaccine and will be incorporated into a trial vaccine:

- A(H1N1): an A/California/7/2009 (H1N1)-like strain, $15 \mu \mathrm{g}$ HA per dose

- A(H3N2): an A/Perth/16/2009 (H3N2)-like strain, $15 \mu \mathrm{g}$ HA per dose

- B: a B/Brisbane/60/2008-like strain, $15 \mu \mathrm{g}$ HA per dose.

The two changes that have been brought in from the 2009 formulation are: (i) replacement of the seasonal H1N1 subtype by the pandemic subtype - A/California/7/2009 (H1N1); and (ii) the new H3N2 strain - A/Perth/16/2009 (H3N2).

\section{Recommendations for prioritisation of immunisation}

The WHO Strategic Advisory Group of Experts (SAGE) as well as the Advisory Committee for Immunization Practices (ACIP) have advised with respect to immunisation against pandemic virus that prioritisation should take into account not only reduction of morbidity and mortality, especially in high-risk groups, but also reduction of transmission, i.e. epidemiological control and also protection of the integrity of the health care system. Experience in 2009 has taught us that in South Africa two specific risk groups also need special attention - pregnant women and people living with HIV. A further consideration is that incorporation of the pandemic strain into the regular seasonal influenza vaccine means that both pandemic and regular seasonal risk groups will now need to be addressed in a combined recommendation.
The immunisation recommendations of the National Advisory Group on Immunization (NAGI) for South Africa for 2010 are as follows in order of priority:

1. Pregnant women - irrespective of stage of pregnancy.

2. Persons over the age of 6 months with underlying medical conditions predisposing them to complications of influenza, including the following - chronic lung disease, chronic cardiac disease, chronic neurological disease, chronic renal disease, mild to severe diabetes and related metabolic conditions, persons on aspirin therapy.

3. Front-line health care and emergency medical service personnel who come into direct contact with patients.

4. HIV-infected adults with a CD4 count above 100 cells $/ \mu 1$ and all HIV-infected children 6 months to 5 years of age.

5. Caregivers of infants less than 6 months of age in day-care centres.

6. All individuals over the age of 65 years.

7. Children 6 months to 5 years of age.

8. Persons between 5 years and 24 years of age living in hostels, boarding schools and similar institutional settings.

\section{Dosage}

- Adults: 1 dose IM.

- Children ( $<12$ years): 1 dose IM.

- Children $<9$ years who have never been vaccinated should receive 2 doses 1 month apart.

- Children less than 3 years of age should receive half the adult dose on two occasions separated 1 month apart.

\section{Contraindications}

1. Persons with a history of severe hypersensitivity to eggs.

2. Persons with acute febrile illnesses should preferably be immunised after symptoms have disappeared.

\section{Timing}

Vaccines should be given sufficiently early to provide protection for the winter. A protective antibody response takes about 2 weeks to develop.

Evidence of an earlier outbreak of pandemic H1N1 may necessitate earlier administration of vaccine. 


\section{SAMJ FORUM}

Table I. Recommended dosage of antiviral agents for treatment

\begin{tabular}{|l|l|l|l|}
\hline Age group & Weight & Oseltamivir dosage & Zanamivir dosage* \\
\hline Adults & & $75 \mathrm{mg}$ twice a day & Two $5 \mathrm{mg}$ inhalations (10 mg total) twice a day \\
\hline Children & $\leq 15 \mathrm{~kg}$ & $30 \mathrm{mg}$ twice a day & \multirow{2}{*}{$\begin{array}{l}\text { Two } 5 \mathrm{mg} \text { inhalations (10 mg total) twice a day } \\
\text { (only in children aged } 12 \text { years or older) }\end{array}$} \\
\cline { 2 - 3 } & $15-23 \mathrm{~kg}$ & $45 \mathrm{mg}$ twice a day & \\
\cline { 2 - 3 } & $24-40 \mathrm{~kg}$ & $60 \mathrm{mg}$ twice a day & \\
\cline { 2 - 3 } & $>40 \mathrm{~kg}$ & $75 \mathrm{mg}$ twice a day & \\
\hline
\end{tabular}

*Recommended duration of treatment is 5 days. Zanamivir is only registered for children $\geq 12$ years of age.

Table II. Recommended dosage of antiviral agents for prophylaxis of high-risk contacts of confirmed, probable or suspected pandemic influenza A(H1N1) 2009 cases*

\begin{tabular}{|c|c|c|c|}
\hline Age group & Weight & Oseltamivir dosage* & Zanamivir dosage* \\
\hline Adults & & $75 \mathrm{mg}$ once a day & Two $5 \mathrm{mg}$ inhalations ( $10 \mathrm{mg}$ total) once a day \\
\hline \multirow[t]{4}{*}{ Children } & $\leq 15 \mathrm{~kg}$ & $30 \mathrm{mg}$ once a day & \multirow{4}{*}{$\begin{array}{l}\text { Two } 5 \mathrm{mg} \text { inhalations ( } 10 \mathrm{mg} \text { total) once a day } \\
\text { (only in children aged } 12 \text { years or older) }\end{array}$} \\
\hline & $15-23 \mathrm{~kg}$ & $45 \mathrm{mg}$ once a day & \\
\hline & $24-40 \mathrm{~kg}$ & $60 \mathrm{mg}$ once a day & \\
\hline & $>40 \mathrm{~kg}$ & $75 \mathrm{mg}$ once a day & \\
\hline
\end{tabular}

${ }^{*}$ Recommended duration of prophylaxis is 10 days. Zanamivir is only registered for children $\geq 12$ years of age.

\section{Antiviral chemotherapy}

As yet, the pandemic influenza A (H1N1) and seasonal H3N2 and B influenza viruses remain sensitive to oseltamivir (as well as zanamivir). Should the situation change, a further advisory will be issued. The dosages for treatment and post-contact prophylaxis (where indicated) are provided in Tables I and II.

For a more detailed consideration of the management of pandemic influenza A (H1N1) please see the Health Worker's
Handbook: http://www.nicd.ac.za/pubs/communique/2009/ sitrep/Revised_Health_Workers_Handbook_Pandemic_ influenza_H1N1_in_SA_19_08_2009.pdf

Department of Health

Corresponding author: B D Schoub (barrys@nicd.ac.za)

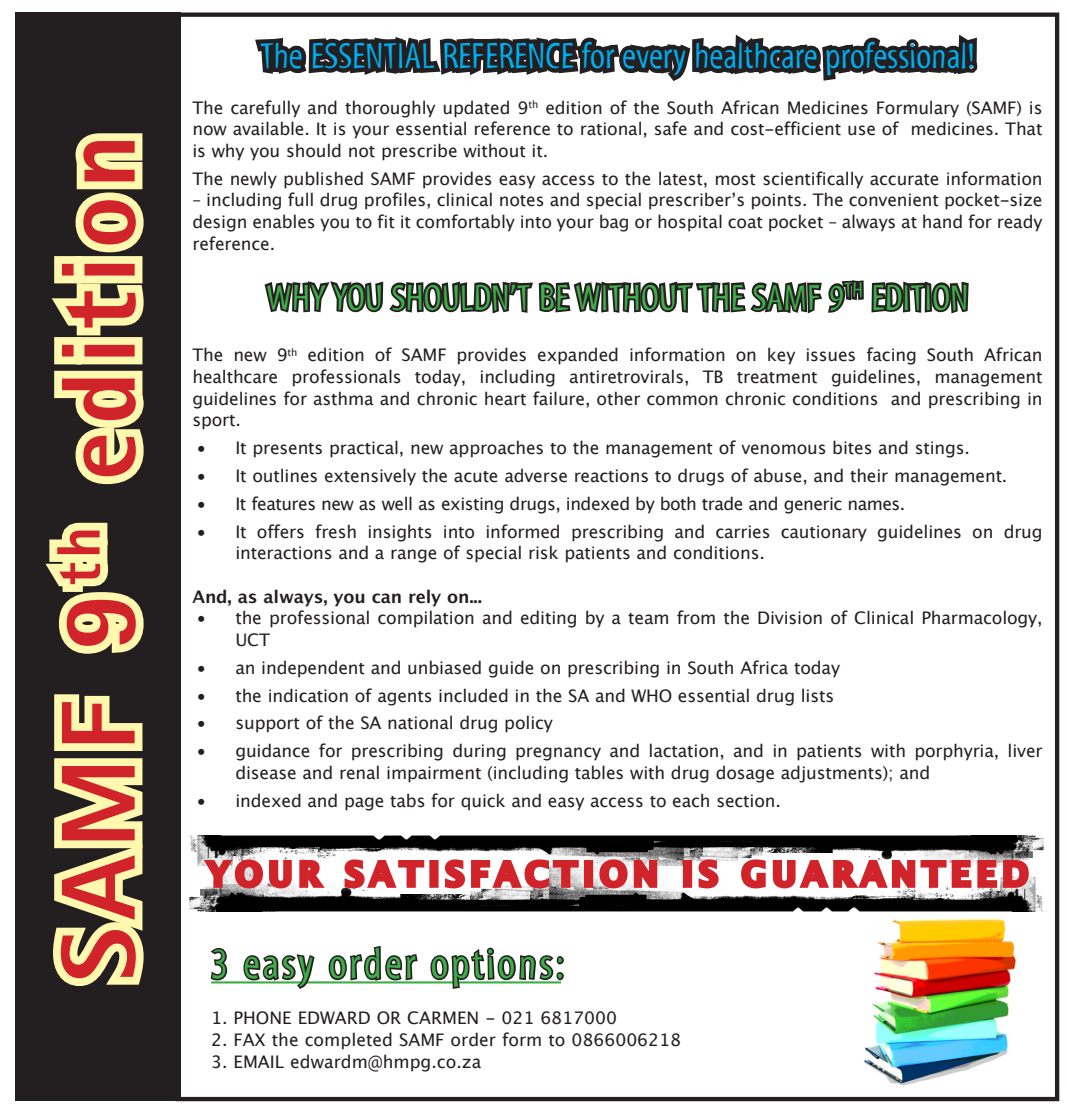

